http://jmscr.igmpublication.org/home/ ISSN (e)-2347-176x ISSN (p) 2455-0450 crossref DOI: https://dx.doi.org/10.18535/jmscr/v8i5.44

\title{
Knowledge regarding fetal movement monitoring among pregnant women attending ANC OPD in a tertiary care centre
}

\author{
Authors \\ Sindhumol PK*, Sethulakshmi Mohan*, Soumya R Nair", \\ Krishna $\mathbf{P}^{\#}$, Jashanpreet Kaur", Arya Anilkumar ${ }^{\#}$ \\ *Asst Prof., CON Pune India \\ ${ }^{\#}$ Students CON Pune, India
}

\begin{abstract}
Intra uterine fetal death is a catastrophic experience for the mother and family. Studies showed that the incidence ranges from 20 to 32 per live birth. $20 \%$ of the cases had unidentified risk factors. Maternal perception of fetal movement is regarded as manifestation of fetal well being. Incidence of still birth is 60 times higher in pregnencies reported with decreased fetal movements. Maternal awareness of fetal perception is a simple self screening technique aids in early identification and associated with improved perinatal outcome. In this context a cross sectional descriptive study was conducted among 60 antenatal women attending an OPD with the objective to assess the knowledge regarding fetal movement monitoring. Structured questionnaire was administered to the subjects selected by simple random sampling. Majority of them (37\%) were in the age group of 23 to 27 yrs.50\% of them were with period of gestation of 36-40 weeks and majority (42\%) had completed their secondary level of education. Even though $17 \%$ and $42 \%$ of subjects possessed good and average knowledge respectively $33 \%$ of the antenatal women had poor knowledge regarding fetal movement monitoring. Study reveals the need of imparting knowledge regarding fetal movement monitoring among antenatal women so as to improve the perinatal outcome.
\end{abstract}

Keyword: Intrauterine fetal death, fetal movement monitoring, knowledge, maternal perception.

\section{Introduction}

Intrauterine fetal death accounts a tragic emotional experience for mother and family. Studies showed that the incidence ranges from 20 to 32 per live birth $^{[1]} .20 \%$ of the cases reported unidentified risk factors leading to IUFD. Retrospective 53\% of woman who had still birth noticed their baby movements had slowed down or stopped but had not reported in time. Fetal movement is an indicator of fetal health status/wellbeing ${ }^{[2]}$. Majority of antenatal women are unaware about fetal movement monitoring. . Incidence of still birth is 60 times higher in pregnencies reported with decreased fetal movements. Maternal awareness of fetal perception is a simple self screening technique aids in early identification and associated with improved perinatal outcome Adequate knowledge about fetal movement monitoring helps in avoiding intra uterine fetal complications and death as the danger can be sensitised early. 


\section{Background of Study}

Reduced fetal movement in pregnancy is a common cause of anxiety and admission during antenatal period. Fetal survillence is always indicated to assess the fetal wellbeing. Anteprtum fetal monitoring helps in reducing perinatal morbidity and mortality. This simple self screening technique permits early identification and timely evaluation and intervention for features at risk of adverse outcome. Voluminous study reveals that decreased perception of fetal movements are a significant indication of IUFD.

\section{Method}

A cross sectional descriptive study was conducted among 60 antenatal women attending an OPD with the objective to assess the knowledge regarding fetal movement monitoring. Non experimental quantitative research approach was adopted. Structured questionnaire was administered to the subjects selected by simple random sampling.

\section{Results}

Analysis done by descriptive statistics. Majority of them (37\%) were in the age group of 23to 27 yrs.50\% of them was with period of gestation of
36-40 weeks and majority (42\%) had completed their secondary level of education. Even though $17 \%$ and $42 \%$ of subjects possessed good and average knowledge respectively $33 \%$ of the antenatal women had poor knowledge regarding fetal movement monitoring.

Table 1: Sociodemographic Data

\begin{tabular}{|l|c|c|}
\hline Variable & \multicolumn{2}{|c}{$\mathrm{n}=60$} \\
\hline Age (years) & Category & Number \\
\hline \multirow{4}{*}{$\begin{array}{l}\text { No of previous } \\
\text { deliveries }\end{array}$} & $23-27$ & $16(27)$ \\
\cline { 2 - 3 } & $28-32$ & $22(37)$ \\
\cline { 2 - 3 } & $33 \&$ above & $17(280$ \\
\cline { 2 - 3 } & 0 & $21(35)$ \\
\cline { 2 - 3 } & 1 & $25(42)$ \\
\hline Period of gestation & $28-32$ wks & $13923)$ \\
\cline { 2 - 3 } & $32-36$ wks & $20(33)$ \\
\cline { 2 - 3 } & $36-40$ wks & $27(45)$ \\
\cline { 2 - 3 } & .40 wks & 0 \\
\hline Educational \\
qualification & Illeterate & $2(3)$ \\
\cline { 2 - 3 } & Primary & $19(32)$ \\
\cline { 2 - 3 } & Secondary & $25(42)$ \\
\cline { 2 - 3 } & Graduation \& & $14(230$ \\
& above & \\
\hline Type of family & Nuclear & $21(35)$ \\
\cline { 2 - 3 } & Joint & $39(65)$ \\
\hline
\end{tabular}

Figures in parecenthesis represent percentage.

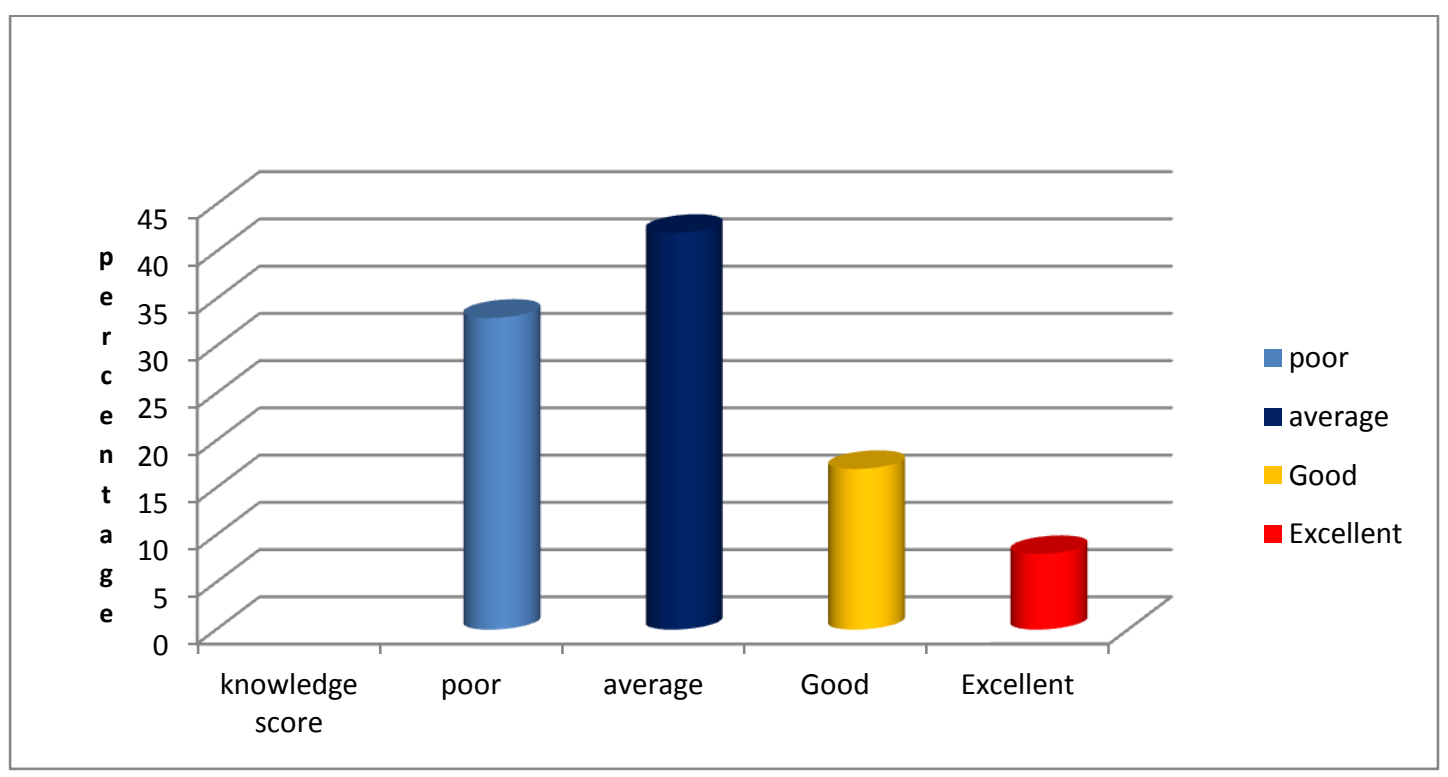

Fig 1: knowledge score category of respondents. 


\section{Conclusion}

Maternal perception of fetal movements, the oldest and most commonly used method is regarded as manifestation of fetal wellbeing. Raising maternal awareness of fetal movement monitoring leads to decrease in perinatal mortality and morbidity. The study highlights the knowledge of antenatal women regarding fetal monitoring. The study concludes that only few subjects had 5(8\%) and 11(17\%) good and excellent knowledge regarding fetal movement monitoring. Study throws light towards the essentiality of educating the significance of fetal movement monitoring.

\section{References}

1. Winge BA et al, Analysis of count to ten fetal movement charts- A prospective study cohort study. BJOG;2011.

2. Pearson JF, Weaver JB, fetal activity and fetal wellbeing; an evaluation. British Medical Journal;1976

3. Hijazi ZR, East CE. Factors affecting maternal perception of fetal movement. Obstet Gynecol Surv;2009.

4. Heazell AE, Frojen JF, Methods of fetal movement counting and the detection of fetal compromise. Journal of obstetrics and gynecology.2008.

5. Radestad I. Fetal movements in the third trimester-important information about wellbeing of thr fetus. Sexual and Reproductive Healthcare, 2010

6. Frojen JF, Heazell AE, Tveit JV, Saastad E, Fretts R c, Flenady V. Fetal Movement Assessment. Seminar perinatology,2008.

7. WHO recommendation on daily fetal movement counting. March 2018

8. Camillee HR, Adriene G, John AH, A cross sectional study of maternal perception of fetal movements and antenatal advice in a general pregnant population, using a qualitative framework. BMc Pregnancy and Childbirth.2013. 